Çukurova Üniversitesi Mühendislik Mimarlık Fakültesi Dergisi, 35(4), ss. 983-991, Aralık 2020

Çukurova University Journal of the Faculty of Engineering and Architecture, 35(4), pp. 983-991, December 2020

\title{
LiDAR Verisi Yardımıyla Otomatik Dalga Boyu Bandı Yaklaşımı Kullanılarak Hiperspektral Görüntülerde Spektral Değişkenliğin Azaltılması
}

\author{
Sevcan KAHRAMAN ${ }^{1^{*}}$ \\ ${ }^{1}$ İstanbul Gelişim Üniversitesi, Mühendislik ve Mimarlık Fakültesi, Elektrik Elektronik \\ Mühendisliği Bölümü, İstanbul
}

Geliş tarihi: 09.10 .2020

Kabul tarihi: 23.12 .2020

$\ddot{\mathbf{O z}}$

Hiperspektral (HS) ve kızı̈ötesi (Light Detection and Ranging-LiDAR) algılayıcıları en yeni uzaktan algılama teknolojilerindendir. Son yıllarda, hiperspektral karışım giderimi analizi uzaktan algılama uygulamalarında büyük bir önem kazanmıştır. Spektral değişkenlik hiperspektral görüntülerde bazı nedenlerden dolayı meydana gelebilmektedir. Bu spektral değişkenlik hiperspektral görüntü analizinde ciddi bolluk değeri tahminleme hatalarına sebep olabilmektedir. LiDAR algılayıcısı spektral değişkenlikten etkilenmeyen Dijital Yüzey Modeli (DSM) bilgisini sunmaktadır. Bu çalışmada, hiperspektral görüntülerde spektral değişkenliği azaltmak için Kararlı Bölge Karışım Giderimi (Stable Zone Unmixing-SZU) yaklaşımı LiDAR-DSM verisinin kümeleme bilgisi kullanılarak uygulanmıştır. Deneysel çalışmalar simulasyon ve gerçek veri setleri üzerinde gerçekleştirilmiş ve spektral değişkenliğin her iki veri setinde de azaltıldığı görülmüş̧ür.

Anahtar kelimeler: Hyperspectral (HS) görüntü; kızı̈ötesi (Light Detection and Ranging-LiDAR) verisi; spektral değişkenlik; SUnSAL-TV; ADMM.

\section{LiDAR-aided Spectral Variability Decreasing in Hyperspectral Imagery Based on an Automated Waveband Selection Approach}

\begin{abstract}
Hyperspectral (HS) and Light Detection and Ranging (LiDAR) sensors are the two of the newest remote sensing technologies. In recent decades, hyperspectral unmixing analysis has achieved a great importance in remote sensing applications. Spectral variability can occur in hyperspectral images due to some reasons. This spectral variability can cause serious abundance estimation errors in hyperspectral image analysis. On the other hand, LiDAR data provides the Digital Surface Model (DSM) data that does not affected by spectral variability. In this study, in order to decrease the spectral variability on hyperspectral imagery, Stable Zone Unmixing (SZU) approach is used by segmenting of LiDAR-DSM information. Experimental results are carried out on simulation and real data sets and spectral variability is reduced in both images.
\end{abstract}

Keywords: Hyperspectral (HS) image; Light Detection and Ranging (LiDAR) Data, spectral variability, SUnSAL-TV, ADMM

*Sorumlu (Corresponding author) yazar: Sevcan KAHRAMAN, sekahraman@gelisim.edu.tr 


\section{GíRiș}

Uzaktan algilamadaki en yeni teknolojiler gözlemlenen sahne ile ilgili detaylı bilgi sunmaktadır. Hiperspektral görüntüler uzaktan algılamada çok çeşitli uygulama alanlarıyla birlikte yaygın olarak kullanılmaktadır. Örneğin, yeryüzü yüzeyinin sınıflandırılması, hedef takibi, çevresel monitörleme vb. Son yıllarda, yüksek uzamsal ve yüksek spektral çözünürlüklü hiperspektral görüntü elde etme, uzaktan algılama çevrelerinde temel bir araştırma alanı olmuştur. Gerçekte hiperpsektral görüntüler bir pikselinde tek tip materyal bulundurabileceği gibi birçok türde materyal de içerebilmektedir. Bu karışık durumda bulunan pikselleri iyi bir şekilde analiz etmek için Lineer Karışım Modeli-LKM (Linear Mixing Model-LMM) [1-2] spektral karışım gideriminde yaygın bir şekilde kullanılmaktadır. LKM; karışım halinde bulunan bir pikselin son elemanlar ve onların ne kadar miktarda bulunduklarını ifade eden bolluk değeri haritalarının lineer bir kombinasyonu şeklinde ifade edilebildiğini kabul etmektedir. Fakat, LKM lineer olmama ve spektral değişkenliği azaltamama gibi dezavantajlara sahiptir. Çünkü, LKM bir tane saf yeryüzü bileşeni için sadece bir tane spektral imza olduğunu kabul etmektedir. Fakat, gerçekte bu doğru değildir. Spektral imzalar daima değişkendir. Spektral değişkenlik çeşitli faktörlerden dolayı meydana gelebilmektedir. Örnek olarak, ışıklandırma [3], çevresel, atmosferik şartlar (su, oksijen, ozon, karbon monoksit ve karbon dioksit) [4], engebeli yüzey ve topografi [5], geçici şartlar, materyalin iç değişkenliği ve gizli parametreler (bitkilerde klorofil konsantrasyonu) [6] sayılabilmektedir.

Eğer spektral değişkenlik uygun seviyede dikkate alınmazsa, bu durum spektral karışım analizinde ciddi tahminleme hatalarına sebep olabilmektedir [7]. İki tür spektral değişkenlik vardır. Bunlar; sınıf-içi spektral değişkenlik ve sınıflar-arası spektral değişkenliktir [8].

Spektral değişkenlik ile ilgili çeşitli literatür çalışmaları bulunmaktadır. Drumetz ve arkadaşları [9] en yeni spektral değişkenlik yaklaşımlarını analiz etmişler ve bu yaklaşımları üç kategoriye ayırmışlardır. Bunlar temel olarak son elemanları küme olarak alan, istatistiksel dağılım olarak alan ve değişkenliği fiziksel model olarak ele alan yaklaşımlardır. Aynı zamanda bu modellerin avantaj ve dezavantajlarını vurgulamışlardır. Somers ve arkadaşları [10] spektral değişkenlik ile ilgili indirgeme yaklaşımlarını incelemişlerdir. Buna ek olarak, spektral değişkenlik ile ilgili baskılama yaklaşımlarının önemini vurgulamışlardır. Zare ve Ho [11] hiperspektral karışım giderimi ve son eleman tahminlemesinde spektral değişkenlik modellerini incelemiş̧ler ve spektral değişkenlik yaklaşımlarını iki gruba ayırmışlardır. Bunlar; son elemanları bir küme şeklinde ve istatistiksel dağılım biçiminde ele alan yaklaşımlardır. Aynı zamanda spektral değişkenliğin geleceği hakkında da yorumda bulunmuşlardır. Theiler ve arkadaşları [12] spektral değişkenliğin nedenlerini tanımlamışlar ve hiperspektral veriyi analiz ederken spektral değişkenliği ele alarak sinyal işleme ve hedef takibi yaklaşımlarının önemini vurgulamışlardır.

Spektral değişkenlik probleminin üstesinden gelmek için literatürde çeşitli teoriler ileri sürülmüştür. Veganzones ve arkadaşları [13] spektral değişkenliği kullanarak her pikselin ölçeklenmesi yardımıyla Genişletilmiş Lineer Karışım Modelini (Extended Linear Mixture Model-ELMM) tanımlamışlardır. Thouvenin ve arkadaşları [14] son eleman değişkenliğini elde etmek için uzamsal değişkenlik gösteren pertürbasyon matrisini dikkate alan Pertürbasyon Lineer Karışım modelini (Perturbed Linear Mixture Model-PLMM) önermişlerdir. Uezato ve arkadaşları [15] spektral karışım gideriminde az olan son elemanların spektral bilgisini kullanma probleminin üstesinden gelmek için çok görevli Gaussian yaklaşımını (Gaussian Process Framework-SUGP) tanıtmışlardır. Hong ve arkadaşları [16] spektral değişkenlik sözlüğünü kullanarak temel ölçekleme faktörü ve diğer spektral varyasyonlarını birleştiren Artırılmış Lineer Karışım Modelini (Augmented Linear Mixture Model-ALMM) sunmuşlardır. Uezato ve arkadaşları [17] her bir sınıfın çoklu son elemanı için hiyerarşik yapıyı ilişkilendiren bir karışım modeli sunmuşlardır. Bu yaklaşım fiziksel bir anlama sahiptir ve her bir sınıfin son eleman spektralarının demetlerini içermektedir. Drumetz 
ve arkadaşları [18] bolluk değeri tahminlemesinde grup seyreklik karışım normlarının kullanımını grup seyrekliğini ifade eden bir kısıtlama ile optimizasyon problemi şeklinde sunmuşlardır. Ibarrola-Ulzurrun ve arkadaşları [19] farklı spektral karışım giderimi modellerinin performansını son elemanların nitelik ve nicelik özelliklerine dayanarak karşılaştırmışlardır. Borsoi ve arkadaşları [20] hiperspektral karışım gideriminde spektral değişkenliği azaltmak için süperpikseller üzerinde veriye bağlı çok skalalı bir model sunmuşlardır. Benhalouche ve arkadaşları [21] LKM için maliyet fonksiyonunu minimize eden ve çarpımsal güncelleme kuralını kullanan pikselden-piksele negatif olmayan matris faktörizasyonu yaklaşımını sunmuşlardır.

LiDAR verisi yatay ve düşey noktaları kullanarak yeryüzü yüzeyinin 3-boyutlu (3D) yapısını sunmaktadır. Bütün hava şartlarında yükseklik, eğim, oryantasyon ve eğrilik gibi geometrik bilgiyi sunabilmektedır [22]. HS ve LiDAR verileri gözlemlenen sahne ile ilgili bütünleşik bilgi sunmaktadırlar. Her iki tür bilgi birlikte kullanılarak materyallerin sınıflandırılması gibi birçok uygulamada daha iyi sonuçlar elde edilebilmektedir Uezato ve arkadaşları [23], hiperspektral görüntünün spektral değişkenliğini radyans bilgisini kullanarak $1 s ̧ 1 k l ı$ ve gölgeli bölgelerde karışım giderimi analizinde fiziksel olarak açıklamak için Işıklandırmada Değişmeyen Spektral Karışım Giderimi Modelini (Illumination Invariant Spectral Unmixing-IISU) LiDAR-DSM verisini kullanarak sunmuşlardır. Kahraman ve arkadaşları [24] hiperspektral karışım gideriminde spektral değişkenliği azaltmak için LiDAR-DSM kümeleme bilgisini özellik çıkarım stratejisi olarak kullanan bir yaklaşım önermişlerdir.

Spektral değişkenlik, bir görüntü boyunca ya da farklı görüntülerdeki materyallerin spektral imzasındaki değişkenlik olarak tanımlanmaktadır. Bir materyal için spektral imzaların değişkenliği hiperspektral karışım giderimi ve sınıflandırmada performans azalmasına neden olmaktadır. $\mathrm{Bu}$ çalışmada, hiperspektral karışım gideriminde LiDAR-DSM verisinin yardımıyla Kararlı Bölge Karışım Giderimi-KBKG dalga boyu bandı seçim yaklaşımı [25] kullanılarak sentetik ve gerçek veri kümelerinde spektral değişkenlik azaltılmaktadır.

Çalışmanın geri kalan kısmı şu şekilde düzenlenmiştir. Başlık 2'de LKM ile birlikte KBKG dalga boyu bandı metodu anlatılarak önerilen yaklaşım anlatılmaktadır. Sentetik ve reel veri setleri üzerinde yapılan deneysel sonuçlar Başlık 3'te verilmiştir. Başlık 3'te elde edilen sonuçlar sunulmaktadir.

\section{MATERYAL VE METOT}

$\mathrm{Bu}$ bölümde sunulan yaklaşımın detayları anlatılmaktadır. Öncelikle Lineer Karışım Modeli, Negatif Olmayan Matris Faktörizasyonu, İkili Parçalama Ağacı ve Kararlı Bölge Karışım Giderimi yaklaşımı anlatıldıktan sonra LiDAR-DSM verisinin kümeleme bilgisi kullanılarak hiperspektral görüntünün çözünürlüğünü nasıl artırdığı anlatılmaktadır.

\subsection{Lineer Karışım Modeli-LKM (Linear Mixing Model-LMM)}

Hiperspektral karışım giderimi, hiperspektral görüntüyü son elemanlar ve onların ne kadar oranda bulunduğunu ifade eden bolluk değeri haritalarına en iyi şekilde ayırmayı amaçlamaktadır. Literatürde farklı türde karışım giderimi modelleri sunulmuştur. Spektral Karışım Giderimi (Spectral Unmixing) [26] en yaygın olarak kullanılan hiperspektral görüntü analiz yöntemlerindendir. $\mathrm{Bu}$ yöntem son elemanlara karşılık gelen bolluk değeri haritalarını en iyi şekilde tahminlemeye çalışmaktadır. Spektral karışım giderimi yöntemlerinden en basit ve en yaygın olarak kullanılan yöntem Lineer Karışım Modelidir-LKM (Linear Mixture Model-LMM) [26]. Lineer karışım modelinde, son elemanların birbirlerinden bağımsız olduğu ve bir hiperspektral görüntünün son elemanlar ve onlara karşılık gelen bolluk değeri haritalarından meydana geldiği kabul edilmektedir. LKM matris formunda aşağıdaki gibi ifade edilebilmektedir [26] (Eşitlik 1):

$\mathrm{Y}=\mathrm{EA}+\mathrm{N}$ 
LiDAR Verisi Yardımıyla Otamatik Dalga Boyu Bandı Yaklaşımı Kullanılarak Hiperspektral Görüntülerde Spektral Değişkenliğin Azaltılması

burada $\mathrm{Y} \in \mathrm{R}^{\mathrm{L} \times \mathrm{M}}$ karışım halinde bulunan hiperspektral görüntüyü, $E \epsilon \mathrm{R}^{\mathrm{L} \times \mathrm{P}}$ son elemanları içeren matrisi, $\mathrm{A} \in \mathrm{R}^{\mathrm{P} \times \mathrm{M}}$ son elemanlara karşılık gelen bolluk değeri matrisini, $\mathrm{N} \epsilon \mathrm{R}^{\mathrm{L} \times \mathrm{M}}$ ise gürültüyü temsil etmektedir. L spektral bant sayısı, $\mathrm{P}$ son eleman sayısı ve $\mathrm{M}$ ise toplam piksel sayısını ifade etmektedir.

\subsection{Negatif Olmayan Matris Faktörizasyonu- NMF (Non-negative Matrix Factorization- NMF)}

Hiperspektral karışım giderimi probleminin çözümü için Negatif Olmayan Matris Faktörizasyonu-NMF (Non-negative Matrix Factorization-NMF) [27] yaklaşımı etkili bir şekilde kullanılmaktadır. NMF yaklaşımı, hiperspektral görüntü matrisi $\mathrm{Y}$ ile onun son elemanlar ve bunlara karşılık gelen bolluk değeri haritaları parçalanma şekli olan $E A$ matrisi arasındaki farkı minimize yapmaya çalışmaktadır. NMF aşağıdaki maliyet fonksiyonu ile ifade edilebilmektedir (Eşitlik 2):

$\mathrm{C}(\mathrm{E}, \mathrm{A})=\frac{1}{2}\|\mathrm{Y}-\mathrm{EA}\|_{\mathrm{F}}^{2} \quad \mathrm{E}, \mathrm{A} \geq 0$

burada $\|.\|_{F}$ Frobenious normu ifade etmektedir.

\subsection{Kararlı Bölge Karıșım Giderimi Yaklaşımı -KBKG (Stable Zone Unmixing Approach $-\mathrm{SZU})$}

Lineer spektral karışım analizi spektral değişkenliği dikkate almamaktadır. Dalga boyu bantları ve spektral özelliklerin alt kümesi kullanılarak son eleman değişkenliği dikkate değer bir oranda azaltılabilmektedir. Spektral değişkenlik probleminin üstesinden gelmek için geliştirilen yöntemlerden biri de Kararlı Bölge Karışım Gideri mi (KBKG) Yaklaşımıdır [25]. KBKG yaklaşımı gözlemlenen sahneden bağımsız en kararlı spektral özellikleri içeren dinamik dalga-boyu bandı seçim protokolü sunmaktadır. $\mathrm{Bu}$ protokol sınıf-içi saçılımı minimize ederken sınıflar-arası saçılımı maksimize etmektedir.
KBKG yaklaşımı spektral değişkenliği azaltan iyi bir karışım giderimi yöntemidir. Bu yaklaşımda karışım analizinde kullanılmak üzere spektral değişkenliğe karşı hassasiyet gösteren spektral özelliklerin seçilmesini gerçekleştiren kararsızlık indeksi-KIN kriteri (InStability Index-ISI) hesaplanmaktadır. KIN kriteri sınıf-içi spektral değişkenliğin sınıflar-arası spektral değişkenliğe oranı şeklinde aşağıdaki gibi tanımlanmaktadır (Eşitlik 3):

$\mathrm{ISI}_{\mathrm{i}}=\frac{\Delta_{\text {smmf-ici,i, }}}{\Delta_{\text {smmtlar-aras }, \mathrm{i}}}=\frac{\mathrm{m}}{\mathrm{m}(\mathrm{m}-1)} \sum_{\mathrm{z}=1}^{\mathrm{m}-1} \sum_{\mathrm{J}=\mathrm{z}+1}^{\mathrm{m}} \frac{1,96\left(\sigma_{\mathrm{z}, \mathrm{i}}+\sigma_{\mathrm{j}, \mathrm{i}}\right)}{\left|\mathrm{R}_{\text {ort }, \mathrm{z}, \mathrm{i}}-\mathrm{R}_{\text {ort } \mathrm{j}, \mathrm{i}, \mathrm{i}}\right|}$

burada $R_{\text {ort,z,i }}$ ve $R_{\text {ort, }, j, i}$ son eleman sinıfları $z$ ve $j$ için, i.ninci dalga boyunda ortalama reflektans değerlerini temsil etmektedir. $\sigma_{\mathrm{z}, \mathrm{i}}$ ve $\sigma_{\mathrm{j}, \mathrm{i}}$ değerleri ise, yine aynı sınıflar için standart sapmayı ifade etmektedir.

KBKG modeli, KIN değerini bir eşik değeri olarak kullanarak her bir piksele Ortalama Hata Kare Kökü (Root Mean Squared Error-RMSE) değerini vermektedir. Böylece en düşük RMSE değerine sahip olan piksel en düşük spektral değişkenliğe sahip anlamına gelmektedir.

KBKG yaklaşımı birkaç adımdan oluşmaktadır: Görüntüde sunulan her bir son eleman için son eleman spektral veri seti toplanır. Mevcut olan spektral veri setine dayanarak sınıf-içi ve sınıflararası değişkenliği dikkate alan KIN kriteri kullanılarak her bir dalga boyu bandının RMSE değeri hesaplanır. Optimal alt küme boyutu belirlenir. Seçilen optimal spektral özelliklerin kümesi karışım analizinde kullanılmaktadır.

KBKG protokölü senaryodan bağımsız olarak kullanılabilen etkili bir spektral karışım analizi yaklaşımıdır. Otomatik dalga boyu bandı seçilerek KBKG yaklaşımıyla beraber spektral değişkenlik azaltılarak karışım analiziyle beraber alt-piksel tahminleme oranı yükseltilebilmektedir. Ayrıca, spektral veriyi karışım analizinde kullanılmak üzere hızlı ve hesaplama olarak etkili algoritma sunmaktadır. 


\section{4. İkili Parçalama Ăgacı (Binary Partition Tree-BPT)}

Az sayıdaki bileşen özelliklerine dayanan İkili Parçalama Ağacı İPA (Binary Partition Tree-BPT) son yıllarda kullanılan en yaygın kümeleme yaklaşımlarından biridir. İPA yaklaşımı $\operatorname{ard} 1 s ̧ ı k$ olarak bölge birleştirmeye dayanmaktadır ve hiperspektral verinin bölgeye dayalı hiyerarşik ifadeesi şeklinde tanımlanmaktadır. IPA hiperspektral veriyi hiyerarşik bölgelere ayırdığı için görüntünün semantik içeriğini de ifade etmektedir [28]. İPA, bir görüntüden çıkartılabilecek anlamlı bölgeler kümesinin bir bütün olarak yapısal ifadesini gerçekleştirmektedir. Böylelikle, bir görüntüden çıkarılabilecek olan aynı özellikteki bölgelerin birleştirilip, yapısal bir bütün şeklinde ifade edilmesini sağlamaktadır.

\subsection{Veri İndirgeme}

Veri indirgeme hiperspektral görüntü işleme ve analizinde hesaplama karmaşıklığını indirgemek için çok fazla kullanılmaktadır [29]. Asner ve Lobell [30] spektral karışım analizinde veri indirgemenin önemini vurgulamışlardır. Dikkatli bir dalga boyu bandı ya da spektral özellik seçim işleminin spektral değişkenliğe karşı gürbüz sonuçlar vereceğini ve böylece sınıflandırma doğruluğunda dikkate değer bir performans artışına neden olacağını vurgulamışlardır. $\mathrm{Bu}$ nedenle, veri indirgeme gerçekleştirimi dikkate değer bir oranda spektral değişkenliğin etkilerini azaltmaktadır. Spektral özellikler ve dalga boylarının alt kümesine odaklanılarak, spektral değişkenlik probleminin üstesinden gelinebilmektedir.

\subsection{Sunulan Yaklaşım}

Bu çalışmada, LiDAR-DSM bölütleme bilgisini bir özellik çıkarımı yaklaşımı olarak hiperspektral görüntülerin bant seçimi işlemi için kullanan yeni bir yaklaşım geliştirilmiştir. Ayrıca, veri indirgeme olarak da görülebilen KBKG bant seçimi yaklaşımı hiperspektral görüntüden özellik çıkarımı için kullanılmıştır.
Elde edilen indirgenmiş spektral özelliklerin spektral değişkenliğe karşı gürbüz sonuçlar verdiği görülmüştür. Bu durum spektral karışım analizinde bolluk değeri tahminlemesini artırmaktadır. Böylelikle, spektral değişkenliği azaltan yeni bir yaklaşım önerilmiştir.

Önerilen yaklaşımın akış diyagramı Şekil 1'de gösterilmektedir.

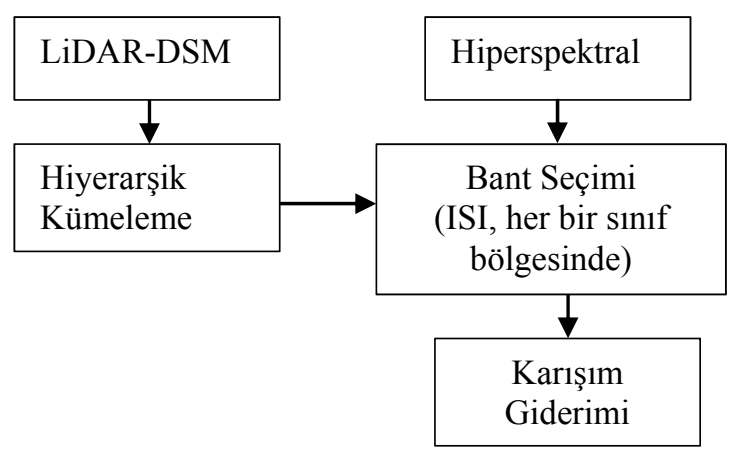

Şekil 1. Sunulan yaklaşım

\section{SAYISAL UYGULAMALAR}

Sayısal uygulamalar LiDAR - DSM verisinin kümeleme bilgisinin bir öznitelik çıkarımı olarak kullanıldığ1 ve böylece bolluk değeri haritalarının tahminlenmesini artırdığını ifade eden simulasyon ve gerçek veri seti deneylerinden oluşmaktadır. LiDAR-DSM verisi üzerinde İPA kümeleme yaklaşımı uygulanılarak bu kümeleme bölgelerine karşılık gelen hiperspektral verisindeki spektral imzalar her bir küme spektraları olarak kullanılmıştır. Böylece, her bir kümenin piksel spektraları hiperspektral veride karşılığ1 olan piksel spektraları olarak kullanılmıştır. Bu veriler kullanarak sınıf-içi ve sınıflar-arası spektral değişkenlik değerleri Somer ve arkadaşları [25]'nin tanıttığı bant seçim yaklaşımı uygulanılarak hesaplanmıştır.

Deneysel çalışmalarda niceliksel geçerleme bolluk değeri haritalarının Ortalama Hata Kare Kökü (Root Mean Square Error-RMSE) değerleri hesaplanarak gerçekleştirilmiştir. RMSE değeri aşağıdaki gibi hesaplanmaktadır (Eşitlik 4): 
LiDAR Verisi Yardımıyla Otamatik Dalga Boyu Bandı Yaklaşımı Kullanılarak Hiperspektral Görüntülerde Spektral Değişkenliğin Azaltılması

$$
\mathrm{RMSE}=\sqrt{\frac{1}{\mathrm{NM}} \sum_{\mathrm{i}=1}^{\mathrm{N}} \sum_{\mathrm{m}=1}^{\mathrm{M}}\left(\mathrm{a}_{\mathrm{mi}}-\hat{\mathrm{a}}_{\mathrm{mi}}\right)^{2}}
$$

burada $a_{m i}$ ve $\hat{a}_{m i}$ gerçek ve tahminlenilen bolluk değeri haritalarıdır. $N$ toplam piksel sayısını ve $M$ ise, son eleman sayısinı ifade etmektedir. Hesaplanalar Intel R Core ${ }^{\mathrm{TM}}$ i7-4770 CPU @ $3.40 \mathrm{GHz}$. özelliğine sahip bilgisayar üzerinde gerçekleştirilmiştir.

\subsection{Sentetik Veri Seti}

Sentetik veri, simulasyon hiperspektral veri setinden ve simulasyon LiDAR-DSM ölçümlerinden oluşmaktadır. Simulasyon verisi olan SIM görüntüsü Birleşik Eyaletler Geolojik Araştırma Spektral Kütüphanesi'nden (United States Geological Survey Spectral Library- USGS) rastgele beş tane son eleman seçilerek oluşturulmuştur. $100 \times 100$ boyutunda [31]'den sentetik bir alt küme görüntüsü kullanılmıştır. Her bir son elemanın 224 tane spektral band bulunmaktadır. Bolluk değeri haritaları negatif olmama ve toplamın bir olması kisitı dikkate alınarak oluşturulmuştur. LKM kullanılarak hiperspektral veri oluşturulmuştur. Daha sonra, bu veri beyaz Gaussian gürültüsü ile SNR (Signal to Noise Ratio) $=20 \mathrm{~dB}$ değerinde bozulmuştur. Bu sentetik görüntüde her bir alan farklı bir yükseklik değerine atanarak sentetik DSM görüntüsü elde edilmiştir. Oluşturulan sentetik hiperspektral verinin görüntüsü Şekil 2'de görülmektedir. Veri

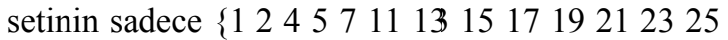
26303335404450 \}numaralı bantları alınmıştır. Gerçekleştirilen deneyde, her bir sınıf içindeki piksel spektraları kullanılarak her bir bant için ISI değerleri hesaplanmıştır. Optimal bantları seçmek için ISI değerleri üzerinde kuantalama işlemi yapıldıktan sonra, bir eşik değeri uygulanılarak bant seçim işlemi gerçekleştirilmiştir. Seçilen bantlar SUnSAL karışım giderimi yaklaşımına [32] girdi olarak verilmiş ve bolluk değeri haritaları hesaplanmıştır.

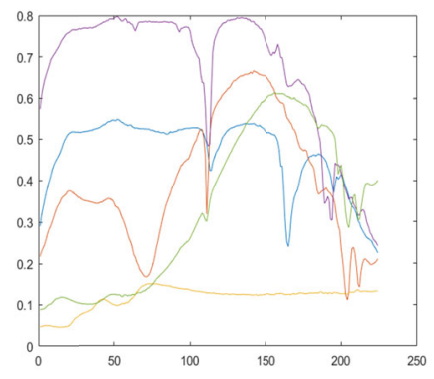

a)

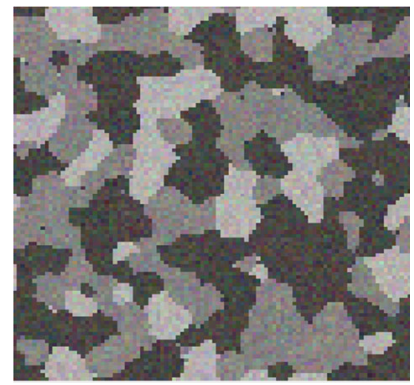

b)

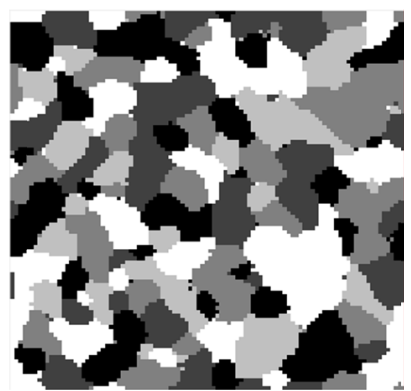

c)

Şekil 2. Simulasyon veri seti a) Simulasyon görüntüden çıkartılan son elemanlar b) Simulasyon görüntünün renkli görüntüsü c) Simulasyon LiDAR-DSM verisi

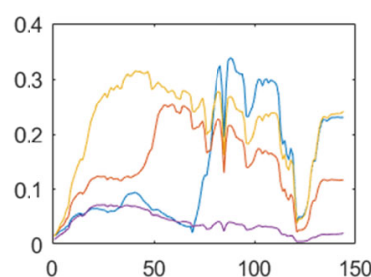

a)

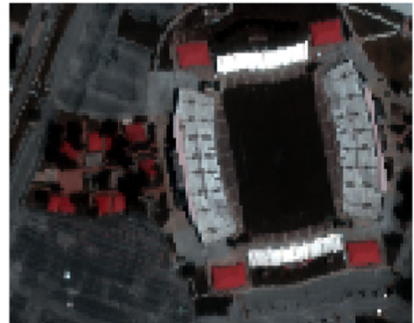

b)

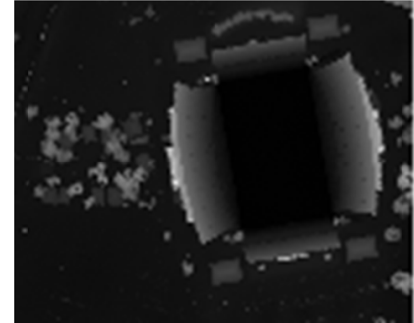

c)

Şekil 3. Gerçek Hauston Üniversitesi Robertson Stadyumu veri seti a) hiperspektral görüntüden çıkartılan son elemanlar b) Gerçek hiperspektral görüntünün renkli görüntüsü c) Gerçek LiDAR-DSM verisi 
Sentetik veri seti üzerinde yapılan deneysel çalışmaların sayısal sonuçları Çizelge 1'de sunulmuştur.

Çizelge1. Sentetik veri bolluk değeri haritaları

\begin{tabular}{|c|c|c|}
\hline \multirow{2}{*}{ Gürültü } & \multicolumn{2}{|c|}{ RMSE } \\
\cline { 2 - 3 } 20 dB & SunsaL & Sunulan Yaklaşım \\
\hline 30 dB & 0,0698 & 0,0012 \\
\hline
\end{tabular}

Çizelge incelendiğinde, sunulan yaklaşımın RMSE değerlerinin farklı gürültülerde de daha iyi sonuç verdiği görülmektedir. Çizelge 1'deki sonuçlardan da görüldüğü gibi uygulanılan yöntem, daha düşük RMSE değerini, yani çözünürlüğü daha da artırılmış hiperpsektral veri elde edilmesini sağlamaktadır.

\subsection{Reel Veri Seti}

Deneyin ikinci k1smı Houston Üniversitesi Kampüsünden, (Texas, USA) Haziran 2012'de alınan veri setinin stadyum bölgesini içeren alt kümesinden oluşmaktadır. $\mathrm{Bu}$ veri $104 \times 128$ boyutunda 144 banttan oluşan bir alt küme görüntüsü olarak [33]'dan alınmıştır. LiDAR görüntüsü ise aynı bölgenin bir gün öncesinde alınmış 2,5 m uzamsal çözünürlüğe sahip olan DSM görüntüsüdür. Şekil 3'de Houston Üniversitesi veri setinin Robertson stadyum bölgesinden alınan bir alt görüntü görülmektedir. $\mathrm{Bu}$ görüntüde yeşil alan, kırmızı çatılar, beton ve asfalt bulunmaktadır. Bu son elemanların spektral imzaları Şekil 3a'da görülmektedir. Stadyum bölgesinin renkli RGB görüntüsü Şekil 3b'de ve gerçek LiDAR-DSM görüntüsü ise, Şekil 3c'de görülmektedir. Hiperspektral görüntülerde gerçek veri setleri üzerinde yapılan çalışmalarda son elemanlar ve onlara karşılık gelen bolluk haritalarının bilgisine sahip olmak çok zor olduğundan genellikle görsel sonuçlar üzerinde deneyler gerçekleştirilmektedir. Ancak, [33]'deki çalışmada kullanılan gerçek veri setinde dört tane son eleman olduğu bilgisi verilmektedir. $\mathrm{Bu}$ çalışmada da bu son elemanlar kullanılmıştır. Gerçek veri seti üzerinde yapılan deneysel çalışma da simulasyon veri setindeki deney gibi gerçekleştirilmiştir. Gerçek veri seti üzerinde yapılan deneysel çalışmaların sayısal sonuçları Çizelge 2'de sunulmuştur.

Çizelge 2. Gerçek veri bolluk değeri haritaları

\begin{tabular}{|l|c|c|}
\hline & \multicolumn{2}{|c|}{ RMSE } \\
\cline { 2 - 3 } Gerçek Veri & SunsaL & Sunulan Yaklaşım \\
\hline
\end{tabular}

Çizelge 2 incelendiğinde, sunulan yaklaşımın RMSE değerinin DSM kullanılmadan gerçekleştirilen karışım giderimine göre daha iyi sonuç verdiği görülmektedir.

Çizelge 1 ve Çizelge 2'deki sonuçlar karşılaştırıldığında sunulan yaklaşımın hem sentetik veri setinde hem de gerçek veri setinde iyi sonuçlar verdiği görülmektedir. Reel veri seit normalize edilmediği için RMSE değerleri 0-1 arasında çıkmamıştır.

\section{SONUÇLAR}

Spektral değişkenlik hiperspektral karışım analizi ve sınıflandırmada zayıf performans sonuçlarına neden olmaktadır. Bu çalışmada sınıf-içi ve sınıflar-arası değişkenliği etkileyen yaklaşımlardan biri incelenmiştir. Bu çalışmada yüksek uzamsal çözünürlüklü hiperpsektral görüntü elde ederken spektral değişkenliği azaltacak yaklaşımlardan birisi olan KBKG bant seçimi yaklaşımı kullanılarak hiperspektral görüntüde spektral değişkenlik azaltılmıştır. LiDAR-DSM verisi spektral değişkenliğe karşı gürbüzdür. Bu nedenle, hiperspektral öznitelik çıkarımında LiDAR-DSM veri setinin kümeleme bilgisi hiyerarşik kümeleme adımında kullanılmıştır. Böylece, hiperspektral görüntüde sadece spektral değişkenliği azaltmakla kalmayıp, karışım giderimi performansını artırdığı da görülmüştür. Deneyler sentetik ve gerçek veri üzerinde gerçekleştirilmiştir. Deneyler sonunda performans karşılaştırması yapılmış ve LiDARDSM bilgisinin hiperspektral karışım gideriminde kullanılmasının daha gürbüz bolluk değeri tahminlemesinin elde edilmesine olanak sağladığı görülmüştür. Daha sonraki çalışmalarda bulut gölgeli alanlardaki spectral değişkenliği azaltacak olan LiDAR verisinin de kullanıldığı farklı yaklaşımlar denenecektir. 
LiDAR Verisi Yardımıyla Otamatik Dalga Boyu Bandı Yaklaşımı Kullanılarak Hiperspektral Görüntülerde Spektral Değişkenliğin Azaltılması

\section{TEŞEKKÜR}

Bu çalışma İstanbul Gelişim Üniversitesi Bilimsel Araştırma Projeleri Uygulama Merkezi tarafından desteklenmiştir. Proje numarası: BP-070220-SK.

\section{KAYNAKLAR}

1. Hu, Y.H., Lee, H.B., Scarpace, F.L., 1999. Optimal Linear Spectral Unmixing. IEEE, Transactions on Geoscience and Remote Sensing, 37(1), $639-644$.

2. Keshava, N., Mustard, J.F., 2002. Spectral unmixing. IEEE Signal Processing Magazine, 19(1), 44-57.

3. Somers, B., Delalieux, S., Verstraeten, W.W., van Aardt, J.A.N., Albrigo, G.L., Coppin, P., 2010. An Automated Waveband Selection Technique for 2010 Optimized Hyperspectral Mixture Analysis, International Journal of Remote Sensing, 31(20), 5549-5568.

4. Healey, G., Slater, D., 1999. Models and Methods for Automated Material Identification in Hyperspectral Imagery Acquired Under Unknown Illumination and Atmospheric Conditions. IEEE Trans. Geosci. Remote Sensing, 37(6), 2706-2717.

5. Adams, J., Sabol, D., Kapos, V., Filho, R., Roberts, D., Smith, M., Gillespie, A., 1995. Classification of Multispectral Images Based on Fractions of Endmembers: Application to Land-cover Change in the Brazilian Amazon. Remote Sensing Environ., 52(2), 137-154.

6. Drumetz, L., Veganzones, M.A., Henrot, S., Phlypo, R., Chanussot, J., Jutten, C., 2016. Blind Hyperspectral Unmixing Using an Extended Linear Mixing Model to Address Spectral Variability. IEEE Trans. Image Process., 25(8), 3890-3905.

7. Uezato, T., Fauvel, M., Dobigeon, N., 2019. Hyperspectral Unmixing with Spectral Variability Using Adaptive Bundles and Double Sparsity, IEEE Transactions on Geoscience and Remote Sensing 57(6), 3980-3992.

8. Zhang, J., Rivard, B., Sanchez-Azofeifa, A., Castro-Esau, K., 2006. Intra- and Inter-class Spectral Variability of Tropical Tree Species at
La Selva, Costa Rica: Implications for species identification using HYDICE imagery. Remote Sensing of Environment, 105, 129-141.

9. Drumetz, L., Chanussot, J., Jutten, C., 2016. Variability of the Endmembers in Spectral Unmixing: Recent Advances. $8^{\text {th }}$ Workshop on Hyperspectral Image and Signal Processing: Evolution in Remote Sensing (WHISPERS), 1-5.

10. Somers, B., Asner, G.P., Tits, L., Coppin, P., 2011. Endmember Variability in Spectral Mixture Analysis: A review. Remote Sensing of Environment, Remote Sensing of Environment, 115, 1603-1616.

11.Zare, A., Ho, K.C., 2014. Endmember Variability in Hyperspectral Analysis: Addressing Spectral Variability During Spectral Unmixing. IEEE Signal Processing Magazine, 31(1), 95-104.

12. Theiler, J., Ziemann, A., Matteoli, S., Diani, M., 2019. Spectral Variability of Remotely Sensed Target Materials: Causes, Models, and Strategies for Mitigation and Robust Exploitation. IEEE Geoscience and Remote Sensing Magazine, 7(2), 8-30.

13. Veganzones, M.A., Drumetz, L., Tochon, G., Dalla Mura, M., Plaza, A., Bioucas-Dias, J., Chanussot, J., 2014. A New Extended Linear Mixing Model to Address Spectral Variability. $6^{\text {th }}$ Workshop on Hyperspectral Image and Signal Processing: Evolution in Remote Sensing (WHISPERS), 1-4.

14. Thouvenin, P., Dobigeon, N., Tourneret, J., 2016. Hyperspectral Unmixing with Spectral Variability Using a Perturbed Linear Mixing Model. IEEE Transactions on Signal Processing, 64(2), 525-538.

15. Uezato, T., Murphy, R.J., Melkumyan, A., Chlingaryan, A., 2016. A Novel Spectral Unmixing Method Incorporating Spectral Variability Within Endmember Classes. IEEE Transactions on Geoscience and Remote Sensing, 54(5), 2812-2831.

16. Hong, D., Yokoya, N., Chanussot, J., Xiang Zhu, X., 2019. An Augmented Linear Mixing Model to Address Spectral Variability for Hyperspectral Unmixing. IEEE Transactions on Image Processing, 28(4), 1923-1938. 
17. Uezato, T., Fauvel Ma., Dobigeon, N., 2019. Hyperspectral Unmixing with Spectral Variability Using Adaptive Bundles and Double Sparsity. IEEE Transactions on Geoscience and Remote Sensing, 1-13.

18. Drumetz, L., Meyer, T.R., Chanussot, J., Bertozzi, A.L., Christian, J., 2019. Hyperspectral Image Unmixing with Endmember Bundles and Group Sparsity Inducing Mixed Norms. IEEE Transactions on Image Processing, 28(7), 3435 - 3450.

19. Ibarrola-Ulzurrun, E., Drumetz, L., Marcello, J., Gonzalo-Martín, C., Chanussot, J., 2019. Hyperspectral Classification Through Unmixing Abundance Maps Addressing Spectral Variability. IEEE Transactions on Geoscience and Remote Sensing, 57(7), 4775 4788.

20. Borsoi, R.A., Imbiriba, T., Bermudez, J.C.M., 2020. A Data Dependent Multiscale Model for Hyperspectral Unmixing with Spectral Variability, IEEE Transactions on Image Processing, 29, 3638 - 3651.

21. Benhalouche, F.Z., Karoui, M.S., Deville, Y., 2019. An NMF-Based Approach for Hyperspectral Unmixing Using a New Multiplicative-tuning Linear Mixing Model to Address Spectral Variability. $2019 \quad 27^{\text {th }}$ European Signal Processing Conference (EUSIPCO), 24-27.

22. Jung, J., Pasolli, E., Prasad, S., Tilton, J., Crawford, M., 2014. A Framework for Land Cover Classification Using Discrete Return LiDAR data: Adopting Pseudo-waveform and Hierarchical Segmentation. IEEE Journal of Selected Topics in Applied Earth Observations and Remote Sensing, 7(2), 491-502.

23. Uezato, T., Yokoya, N., He, W., 2020. Illumination Invariant Hyperspectral Image Unmixing Based on a Digital Surface Model, IEEE Transactions on Image Processing, 29, 3652 - 3664.

24. Kahraman, S., Bacher, R., Uezato, T., Chanussot, J., Tangel, A., 2019. LiDARGuided Reduction of Spectral Variability in Hyperspectral Imagery. $201910^{\text {th }}$ Workshop on Hyperspectral Imaging and Signal Processing: Evolution in Remote Sensing (WHISPERS), 2019.
25. Somers, B., Delalieux, S., Verstraeten, W.W., van Aardt, J.A.N., Albrigo, G.L., Coppin, P., 2010. An Automated Waveband Selection Technique for Optimized Hyperspectral Mixture Analysis, International Journal of Remote Sensing, 31(20), 5549-5568.

26. Bioucas-Dias, J., Plaza, A., Dobigeon, N., Parente, M., Du, Q., Gader, P., Chanussot, J., 2012. Hyperspectral Unmixing Overview: Geometrical, Statistical, and Sparse Regression-based Approaches. IEEE Journal of Selected Topics in Applied Earth Observations and Remote Sensing, 5(2), 354-379.

27. Lee, D., Seung, H., 1999. Learning the Parts of Objects by Non-negative Matrix Factorization. Nature, 401, 788-791.

28. Salembier, P., Garrido, L., 2000. Binary Partition Tree as an Efficient Representation for Image Processing, Segmentation, and Information Retrieval, IEEE Trans. Image Process., Apr., 9(4), 561-576.

29. Tu, T.N., Chen, C.H., Wu, J.L., Chang, C.I., 1998. A Fast Two-stage Classification Method for High-dimensional Remote Sensing Data, IEEE Transactions on Geoscience and Remote Sensing, 36, 182-191.

30. Asner, G.P., Lobell, D.B., 2000. A Biogeophysical Approach for Automated SWIR Unmixing of Soils and Vegetation, Remote Sensing of Environment, 74, 99-112.

31. Uezato, T., Murphy, R.J., Melkumyan, A., Chlingaryan, A., 2016. A Novel Endmember Bundle Extraction and Clustering Approach for Capturing Spectral Variability Within Endmember Classes, IEEE Trans. Geosci. Remote Sens., 54(11), 6712 - 6731.

32. http://www.lx.it.pt/ bioucas/code.htm

33. Drumetz, L., Veganzones, M.A., Henrot, S., Phlypo, R., Chanussot, J., Jutten, C., 2016. Blind Hyperspectral Unmixing Using an Extended Linear Mixing Model to Address Spectral Variability, IEEE Transactions on Image Processing, 25(8), 3890 - 3905. 
